\title{
Símbolos de poder entre las mujeres mayas de la élite. Un análisis iconográfico de los ornamentos femeninos
}

\author{
Cristina Vidal Lorenzo y Esther Parpal Cabanes \\ Universitat de València \\ cristina.vidal@uv.es; esther.parpal@uv.es
}

RESUMEN: La aplicación de la perspectiva de género al estudio del arte maya es relativamente reciente, por lo que, a pesar de que cada vez son más abundantes los escritos que centran su atención en la representación de la figura femenina, aún quedan muchos aspectos pendientes de investigar. Por este motivo, en este artículo nos remontamos a los primeros trabajos destinados a reflexionar en torno a esta temática y que han marcado las bases de las futuras investigaciones, antes de adentrarnos en el tema que nos ocupa: de qué manera los ornamentos, y más concretamente los que se colocaban en torno al cuello y sobre el pecho, contribuían a construir la imagen de poder de las antiguas mujeres mayas. Para ello realizamos un análisis de los tipos más característicos que lucen los miembros de la élite y los ponemos en relación con su contexto, para extraer así conclusiones sobre el significado que tuvo el que también fueran portados por las damas de la corte.

PALABRAS CLAVE: Maya, Mujeres, Género, Ornamento, Collar, Pectoral, Iconografía.

\section{Symbols of Power Held by Elite Maya Women. An Iconographic Analysis of Feminine Ornaments}

ABSTRACT: The study of Mayan art from a gender perspective is relatively recent, so, even though academic works that focus on the representation of the female figure are becoming more prevalent, there are still many outstanding issues to investigate. For this reason, in this article we return to the early works earmarked for reflection on this subject that have marked the foundation of future investigations before we delve into the subject at hand: how the ornaments, and more specifically those that are placed around the neck and chest, helped to build the image of power of ancient Mayan women. We analyse the most characteristic types worn by members of the elite and put them in context, in order to draw conclusions about the significance of them also being worn by the ladies of the court.

KEYWORDS: Maya, Women, Gender, Ornament, Necklace, Pectoral, Iconography.

Recibido: 14 de marzo de 2016 / Aceptado: 1 de mayo de 2016.

\section{El arte maya desde una perspectiva de género}

Desde las primeras reproducciones decimonónicas de personajes femeninos en el arte maya, han sido varios los autores que han ido construyendo a través de sus trabajos, intencionada o fortuitamente, la historia de estas antiguas mujeres. Cuando a finales del siglo XIX, el explorador inglés Alfred P. Maudslay realizó las extraordinarias fotografías de los Dinteles 24 y 25 de Yaxchilán (1974, vol. II, Pls. 86 y 87) y se detuvo en el dibujo de los ornamentos que porta el personaje femenino de ambos dinteles, la célebre Señora Xoc, así como en todos los detalles de su rostro, es indudable que tuvo que llamarle la atención el protagonismo que ostentó este personaje, ataviado con vestido largo y ricamente engalanado [1]. Y aunque en la somera descripción que realiza de estos dibujos y fotografías no menciona explícitamente este hecho (Maudslay, 1974, vol. V, Text

VIDAL LORENZO, Cristina y PARPAL CABANES, Esther: "Símbolos de poder entre las mujeres mayas de la élite. Un análisis iconográfico de los ornamentos femeninos", Boletín de Arte, n. ${ }^{\circ}$ 37, Departamento de Historia del Arte, Universidad de Málaga, 2016, pp. 227-241, ISSN: 0211-8483. 


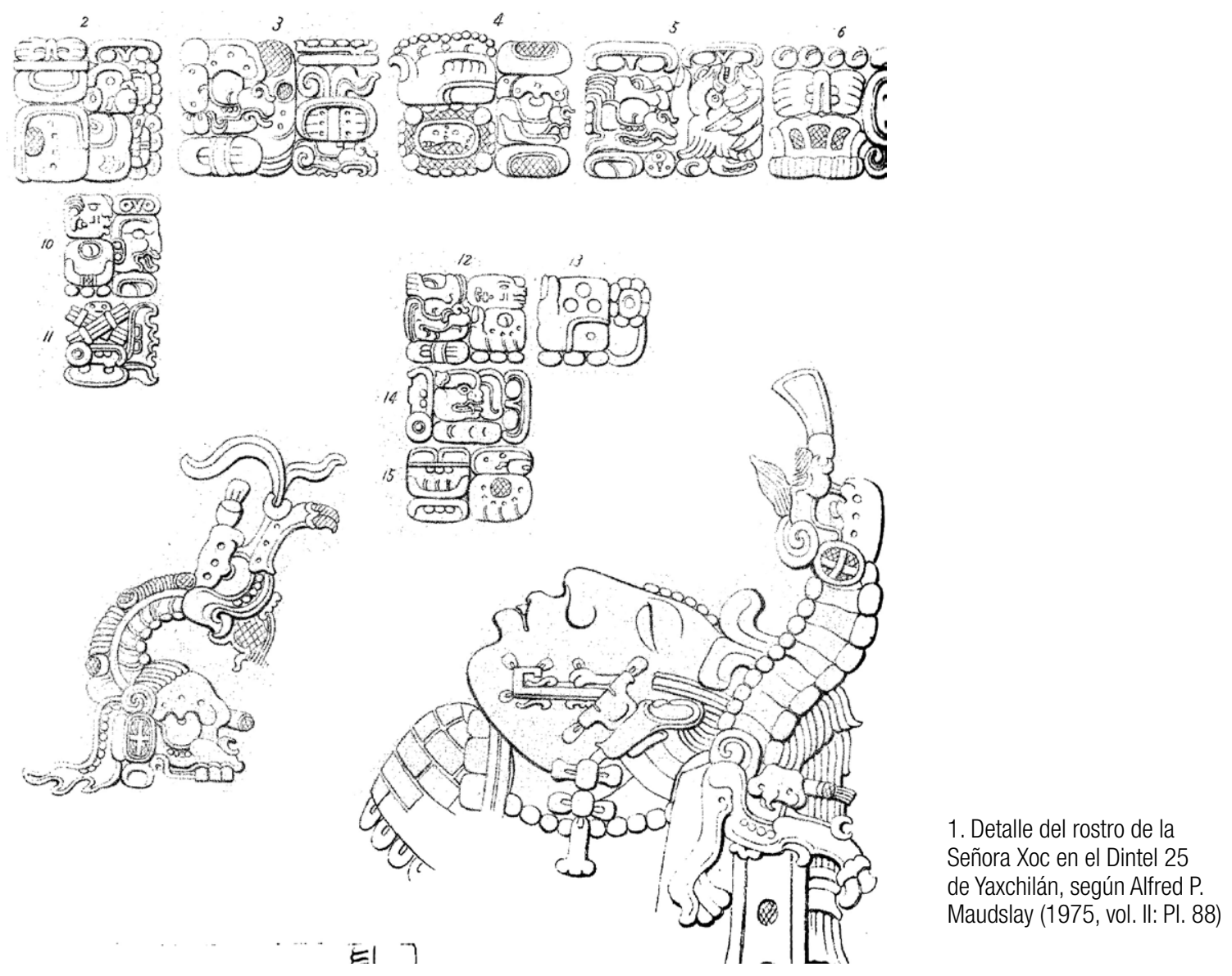

vol. II: 45), es decir, no sabemos si fue consciente de que se hallaba ante la representación de una ilustre mujer de la realeza, estas primeras fuentes gráficas, junto con los dibujos realizados por el explorador francés Désiré Charnay ${ }^{1}$, han sido un valioso aporte a la hora de emprender los estudios sobre las representaciones femeninas en el arte maya [2].

No obstante, hubo de pasar más de medio siglo para que se llevaran a cabo investigaciones de relevancia en este ámbito, las cuales proceden de diferentes disciplinas, destacando entre éstas la historia del arte, la epigrafía, la arqueología, la antropología, la lingüística y la etnografía. Como bien señalan algunas autoras interesadas en el papel que jugaron las mujeres mayas del pasado², fue el trabajo de una brillante investigadora de origen ruso, Tatiana Proskouriakoff (1961), el que se erigió como pionero para los estudios concernientes al género en la cultura maya, al referirse por vez primera a las funciones y contextos propios en los que se desenvolvían las mujeres y en los que poder identificarlas, en contraste con el género masculino. Proskouriakoff pudo llegar a estas conclusiones a partir de la atenta observación de las representaciones masculinas y femeninas de los monumentos escultóricos de la ciudad de Piedras Negras y de su acierto al descubrir, en las inscripciones jeroglíficas que las acompañan, la presencia de nombres precedidos por un glifo con apariencia de rostro de mujer. Ese glifo, Ix, es el prefijo indicador del género femenino en la escritura maya, el cual puede leerse en estos casos como «señora» (Bruhns y Stothert, 1988: 18), (Sharer y Traxler, 2006: 140). Es importante subrayar, como afirma dicha autora, que hasta entonces se pensaba que esas representaciones correspondían a individuos masculinos ataviados como sacerdotes, tal como acabamos de ver en la descripción que realiza Charnay del Dintel 24 de Yaxchilán (véase nota a pie 1), de ahí la importancia de sus aportaciones a la historia del desciframiento de 
la escritura maya y al avance en los estudios sobre género en la América prehispánica. Las siguientes líneas resumen el contenido de sus acertadas reflexiones:

Many consider the skirted and robed figures as those of priests or of male penitents in ceremonial attire, a view largely based on the theory that monuments were time-makers dealing with matters of the calendar astronomy, divination and ritual, from which women were strictly excluded. [...] I have shown that at Piedras Negras there is a pattern of dates that strongly suggests a historical record dealing with the succession of rulers, and if this interpretation of the pattern is correct, not only must we regard the sculptured figures on monuments as portraits of actual persons, but we must give added credence to the idea that the robed figures among them are women, for in dynastic matters family connections and descent are bound to play an important part, and there are indications that Maya culture was not without matriarchal traits (Proskouriakoff, 1961: 82).

Quince años más tarde, Joyce Marcus (1976) iría más lejos al lograr identificar en los textos epigráficos la presencia de nombres femeninos asociados a glifos emblema de entidades políticas mayas, indicativos de que se habían llevado a cabo matrimonios reales. Por lo general, en estas alianzas dinásticas se producía el enlace entre una princesa originaria de una determinada localidad con el gobernante de otra ciudad, en muchas ocasiones situada a una gran distancia. Significaba esto que las mujeres mayas cumplieron un destacado papel en el complejo escenario de las relaciones políticas del Clásico maya, hasta entonces totalmente ignorado y exclusivamente relegado a su función de esposas y reproductoras.

El paulatino descubrimiento en las décadas siguientes de nuevos monumentos escultóricos y otros soportes plásticos con inscripciones jeroglíficas, aunado a la mayor comprensión de esta compleja escritura, ha permitido dar visibilidad y conocer los nombres de varias de estas mujeres que participaron activamente en los acontecimientos políticos de su época, llegando incluso a reinar por derecho propio (Josserand, 2011). Gracias a ello, trabajos dedicados a profundizar en la historia de las dinastías mayas, como el libro publicado en el año 2000 por Simon Martin y Nikolai Grube, Chronicle of the Maya Kings and Queens, ya incluye

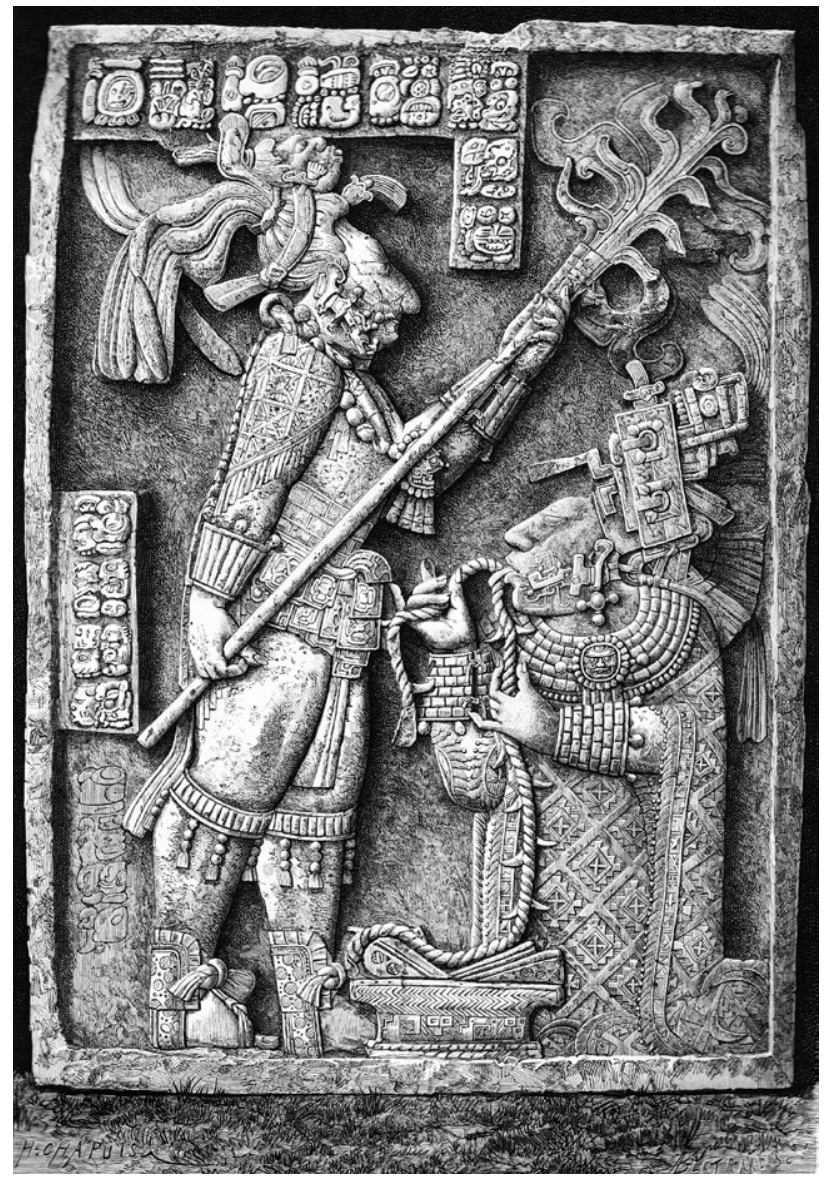

2. Dintel 24 de Yaxchilán dibujado por Désiré Charnay (1885: 393)

en su título el término «reinas», al tiempo que nos ofrece un panorama sobre las relaciones entre géneros en el seno de la élite maya.

Por otro lado, los avances en el desciframiento de la escritura maya han discurrido de forma paralela al incremento de los análisis de las representaciones femeninas desde la iconografía. Al poder poner en relación las menciones epigráficas con las imágenes se abrió un campo de investigación sumamente atractivo para los historiadores del arte, del cual se derivan novedosos resultados. Muchos de ellos han sido publicados en monografías dedicadas a estudios de género en la antigua América, siendo Virginia Miller la primera en introducir el término "género» en un ya célebre trabajo colectivo sobre arte precolombino The Role of Gender in Precoloumbian Art and Architecture (Miller, ed., 1988). 
A partir de entonces, los estudios de género en la cultura maya han ido proliferando de manera sustancial y haciéndose un lugar a nivel académico. Sin embargo, continuamos enfrentándonos a dos cuestiones. La primera de ellas es que, pese a que contamos con importantes precedentes, se trata de un ámbito de estudio todavía embrionario, puesto que durante muchos años las investigaciones sobre la sociedad maya han estado impregnadas inevitablemente de un punto de vista androcéntrico, por lo que aún son muchos los aspectos pendientes de investigar y contrastar. $Y$, en segundo lugar, aunque los estudios de este tipo buscan hacer visible la figura de las mujeres mayas en su sociedad y dar a conocer el papel que desempeñaron, las interpretaciones de los resultados obtenidos ofrecen puntos de vista dispares acerca de las relaciones entre géneros de los mayas del pasado. Esta diversidad de opiniones puede agruparse en dos corrientes o líneas de pensamiento principales. Por un lado, los investigadores más tradicionales han defendido, y defienden, la idea de una sociedad patriarcal en la que la mujer ocupó, al igual que ocurrió en otras muchas civilizaciones, un escalafón inferior en la jerarquizada pirámide social, siendo excepcionales los casos en los que llegaron a ejercer algo de poder. Por otra parte, han ido surgiendo cada vez más estudiosos que apuestan por una situación diferente al considerar que la mujer maya desarrolló labores paralelas a las del hombre, siendo ambas complementarias e igualmente necesarias. De manera que, según esta corriente más innovadora, las mujeres mayas gozaron, al menos en las altas esferas sociales, de una posición más cómoda e influyente de lo que hasta hace no muchos años se había creído.

Las teorías que argumentan que el rol de la mujer estuvo condicionado por el dominio masculino se inician con autores como John Molloy y William Rathje (1974) quienes, desde la década de los años setenta, han abogado por la existencia de un modelo social en el que la mujer no era más que un bien empleado en las estrategias políticas y económicas de los gobernantes (siempre masculinos), ofrecida en matrimonio con el fin de adquirir unos determinados poderes o dominios ${ }^{3}$. Con el paso del tiempo, otros nombres se han ido sumando a la lista de académicos que admiten la existencia de contradicciones en la comprensión de la sociedad maya a la hora de reconocer el poder de las mujeres. En este caso se encuadran estudios como el de June Nash (2002), quien en el prefacio al libro editado por Traci Ardren, Ancient
Maya Women, sostiene que el análisis de restos óseos humanos hallados en el registro arqueológico revelan una eminente diferencia nutricional entre el género masculino y el femenino, siendo este último más pobre. Asimismo, acomete contra las teorías que defienden la descendencia matrilineal, recalcando que los indicios desvelan el paso de la herencia de padres a hijos, en contraste con los casos excepcionales en que el sistema de sucesión se realizaba por la línea materna.

Por su parte, otras autoras, a partir de los análisis que realizan de fuentes literarias (Barba, 2011: 192) e iconográficas (García Valgañón, 2015: 523), llegan a la conclusión de que, en todo caso, el sexo femenino pudo haber gozado de una consideración comparable a la de los varones durante la vejez, período del ciclo vital durante el cual disminuyen las diferencias físicas más aparentes entre hombres y mujeres, y en el que éstas ya carecen de la menstruación, un proceso fisiológico considerado en muchas culturas, entre ellas la que nos ocupa, como contaminante y «relacionado estrechamente con la muerte debido al desperdicio que mensualmente se lleva a cabo cuando no hay concepción» (López, 2011: 231).

En síntesis, las teorías sobre la malnutrición femenina, el escaso reconocimiento de las funciones de la mujer en las etapas anteriores a su vejez, su excepcional aparición como figuras poderosas, así como su menor representación en el arte y en las menciones epigráficas, constituyen, según esta línea de pensamiento, las evidencias de una civilización predominantemente patriarcal, cuestionando así el liderazgo femenino en las esferas del poder.

Por el contrario, esta perspectiva varía en los estudios de otros autores pertenecientes a una segunda corriente de intelectuales que trata de despojarse de los prejuicios espacio-temporales que indudablemente condicionan al investigador actual, para revisar la historia de la cultura maya prestando atención, exclusivamente, al colectivo femenino. El origen de estas ideas se localiza en obras como The Blood of Kings: Dynasty and Ritual in Maya Art, de Linda Schele y Mary E. Miller (1988), en la que sus autoras subrayan la trascendencia del rol de la mujer maya como madre legitimadora del linaje real. Reivindican así la importante labor femenina en la élite maya a la hora de perpetuar el poder de una dinastía, aspecto probado mediante la epigrafía y los análisis iconográficos, e insisten en la igualdad y complementariedad de las funciones desempeñadas tanto por hombres como por mujeres. 
Kathryn Josserand (2011)4 y Julia Hendon (1997) se suman a este grupo de investigadores. La aportación principal de la primera reside en destacar cómo las mujeres nobles no sólo participaron junto a sus maridos en las ceremonias y rituales sagrados, sino que además estuvieron notablemente implicadas en el desarrollo de las tramas familiares y políticas de la corte en beneficio de los suyos, promoviendo ventajosas alianzas y determinando la herencia del poder. Por su parte, Hendon, despunta al poner de relieve al colectivo femenino, más allá del género, como individuos que, además de ser mujeres, pertenecieron a grupos sociales mucho más condicionantes en el desarrollo vital maya, como fue el rango social. Además, fue pionera al realizar un detallado análisis de los materiales arqueológicos procedentes de una residencia de la élite en Copán, demostrando que algunas mujeres de alto rango dedicaban gran parte de su tiempo a actividades productivas importantes para la economía de su ciudad, entre ellas la producción textil (Ardren, 2002: 9). En sintonía con la citada autora, en 2005 Stanley Guenter y David Freidel retoman la cuestión de la igualdad determinada por el grupo social y no por el sexo, y ese mismo año Cristina Vidal defiende la hipótesis de que las mujeres de la élite también estaban involucradas en la preparación de colorantes para el tinte y de pigmentos para la pintura, sin descartar el que existieran mujeres pintoras-escribas, es decir, aquéllas que habrían tenido reservado el exclusivo privilegio del conocimiento de la escritura (Vidal, 2005).

Para concluir, es imprescindible mencionar a Rosemary Joyce como paradigma en los estudios de género maya de esta segunda corriente. Sus aportaciones han resultado tan determinantes que, en 2013, varios especialistas, a los cuales había influenciado a lo largo de su carrera, decidieron dedicar una obra completa a reconocer su labor y destacar su contribución a esta materia a través de una colección de ensayos, Género y Arqueología en Mesoamérica. Homenaje a Rosemary A. Joyce (Rodríguez-Shadow y Kellog, 2013). De entre sus copiosos estudios, cabe destacar que en los años noventa, Joyce (1996) participó en el libro editado por Rita Wright sobre género y arqueología, con una contribución acerca de la importancia de las representaciones artísticas mayas como medio para extraer algunos principios sobre el género, y al mismo tiempo elemento de diferenciación entre las élites capaces de retratarse en los diferentes soportes artísticos, y quienes no podían permitirse semejante privilegio. De esta manera mantiene que el arte tenía una función propagandística al servicio del poder, donde además, se podían distinguir los papeles asociados a cada género. Asimismo, aunque en este aspecto no es la única, establece las bases que diferencian entre el sexo natural y el género construido en el ámbito social (Rodríguez-Shadow y Kellog, 2013: 19-20). No obstante, la obra en la que realmente desplegará todo su arsenal de conocimientos e ideas, y que se constituirá como paradigma en el estudio de la arqueología de género mesoamericana, fue Gender and Power in Prehispanic Mesoamerica (Joyce, 2001), donde da cabida a otras formas de género y prácticas sexuales, ampliando los pensamientos tradicionales basados en ideas preconcebidas sobre el período Clásico maya. En este caso todavía es más contundente cuando defiende la función del arte como elemento de divulgación política, al referirse a las estelas mayas.

Partiendo de estos estudios previos, a los que hay que sumar los de muchos otros autores que han abordado este tema desde diferentes disciplinas ${ }^{5}$, pretendemos con nuestro trabajo contribuir al estudio de la mujer maya desde una perspectiva de género a partir del análisis e interpretación iconográfica de una selección de obras, siendo ésta una línea de investigación que estamos desarrollando en el Departamento de Historia del Arte de la Universidad de Valencia. En esta ocasión nos centraremos en el análisis de los ornamentos exhibidos por las mujeres mayas de la élite, al considerar estos como elementos simbólicos susceptibles de aportarnos información acerca de la construcción del género en la sociedad maya clásica.

\section{La indumentaria y el adorno como símbolos de poder e identidad de las mujeres mayas de la élite}

A lo largo de la historia de las antiguas civilizaciones, como la egipcia o las mesopotámicas, una de las principales inquietudes albergadas por los soberanos ha sido la de inmortalizar la memoria de su paso por el poder mediante la construcción de edificaciones monumentales y el patrocinio de obras de arte, muchas de ellas acompañadas de inscripciones destinadas a dejar constancia de su grandeza u otros hechos señalados. Y todo ello, no sólo con la intención de perpetuar la gloria de sus protagonistas, sino que estas 


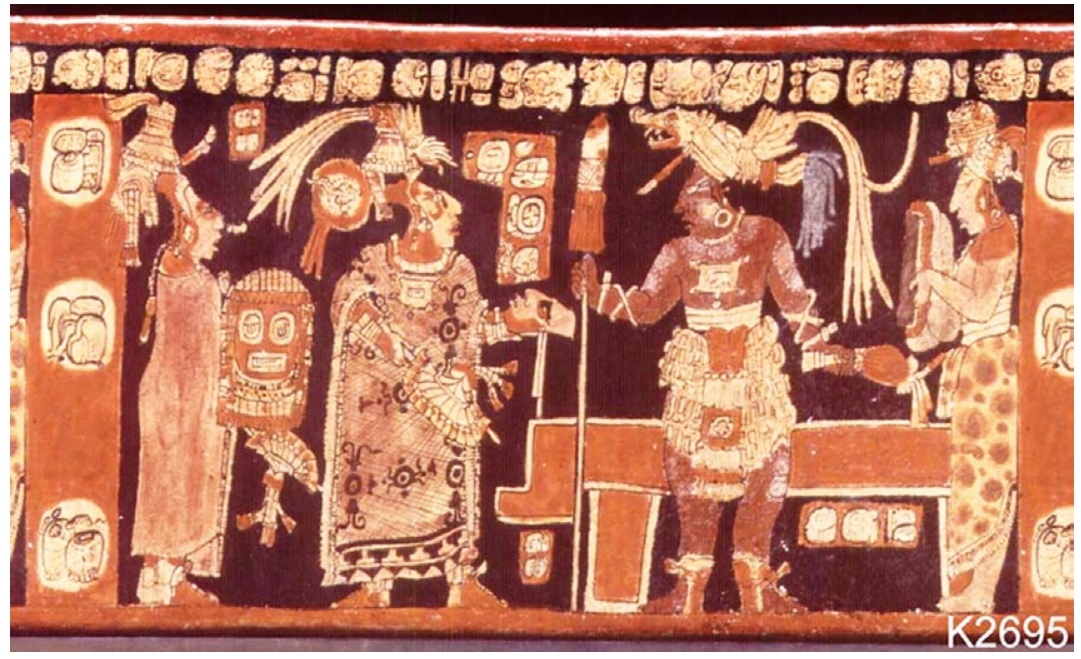

3. Escena protagonizada por los reyes de Tikal, representada en el «Vaso Salomé» (C) Justin Kerr, K2695, www.mayavase.com) manifestaciones artísticas poseían, además, una indiscutible intencionalidad política, y generalmente también religiosa, en el momento en el que se originaron. En este sentido, los mandatarios mayas no fueron diferentes de los de otras culturas, por lo que los artistas al servicio de la corte se encargaron de retratarlos con todos aquellos símbolos legitimadores de su autoridad política y linaje dinástico.

Dichos elementos o atributos de poder incluyen desde cetros, pasando por los espejos de obsidiana y otros instrumentos de carácter religioso, hasta la elaborada indumentaria, los sofisticados tocados y las ricas joyas que lucían, tal como se puede observar en la escena pintada en el vaso cerámico K2695, popularmente conocido como «Vaso Salomé» [3].

A grandes rasgos, el modelo de representación característico de los dirigentes varones en las escenas de palacio habitualmente plasmadas en las vasijas polícromas- lo componía un faldellín que caía desde la cintura hasta la altura de las rodillas aproximadamente, y se ceñía al cuerpo mediante un cinturón. No obstante, existen numerosas variantes en lo que respecta a esta prenda, de hecho, en algunas ocasiones esta era sustituida por un sencillo taparrabos formado por un cinturón y dos piezas textiles que cubrían la parte frontal y trasera del cuerpo de su portador. Normalmente, el pecho y los hombros permanecían desnudos, si bien solían estar cubiertos por pintura corporal que por lo general se extendía también por toda la nuca y el rostro (Vázquez de Ágredos, Vidal y Horcajada, en prensa). Asimismo, en las escenas en las que las piernas se muestran al descubierto se distinguen más patrones de pintura corporal. En cuanto a los pies, en las ocasiones en las que no van descalzos, aparecen cubiertos con sandalias de piel anudadas. El resto del atuendo lo completan los tocados y las joyas. Cabe señalar que para los actos ceremoniales y otros acontecimientos públicos esculpidos en los monumentos pétreos (dinteles y estelas, principalmente), los soberanos se mostraban con un atuendo mucho más complejo que solía incluir tocados y penachos muy sofisticados, y capas de algodón o de piel que, ajustadas al cuello, descendían por sus hombros y espalda hasta arrastrar por el suelo, o bien capas cortas profusamente decoradas, a las que algunos autores denominan quechquémitl ${ }^{6}$ [2].

Por su parte, las mujeres, especialmente las reinas, se vestían con una prenda muy particular conocida con el nombre náhuatl de huipil. Semejante a una túnica, el huipil ceremonial, tal como se aprecia en las imágenes, cubría el cuerpo desde los hombros hasta los tobillos y estaba compuesto por una pieza unida lateralmente mediante costuras, dejando dos aberturas para los brazos y una central para la cabeza. Lo habitual es que debajo de esta prenda se distinga la presencia de otra pieza de ropa a modo de falda, que se ceñía alrededor de la cintura mediante una faja. Los diseños de huipil variaban en función del tipo de corte de cuello efectuado, de los remates laterales, de la gama de colores empleada, de los motivos decorativos y de la transparencia del tejido [4]. Del mismo modo que ocurre en el caso de los varones, existían otros atuendos 
específicos tanto para la vida cotidiana como para determinados rituales o acontecimientos ${ }^{7}$.

Las mujeres nobles, al igual que los hombres, solían calzar sandalias de piel que se ataban a los tobillos, al tiempo que engalanaban sus brazos, rostro y cuello mediante ornamentos cuya suntuosidad variaba en función de la jerarquía de quien los lucía. Lo mismo ocurría con los adornos en el cabello, desde sencillos recogidos mediante cintas y, en ocasiones, alguna diadema, hasta los tocados más ostentosos repletos de atributos sagrados. Asimismo, cubrían sus cuerpos y sus rostros con pigmentos de color dando lugar a diferentes diseños que también contribuyeron a construir su imagen.

Como decíamos, en la búsqueda por aproximarnos al papel que desempeñaron a nivel político las mujeres mayas de la antigüedad hemos escogido los ornamentos como elementos iconográficos cuya diversidad y capacidad comunicativa nos permiten obtener interesantes conclusiones acerca de nuestro objeto de estudio, sobre todo si se contrastan con los adornos que ostentan los varones. Hemos de puntualizar que con el término ornamento nos referimos a aquellos elementos materiales que se colocaban sobre el cuerpo y que, aunque en ocasiones implicaban una alteración física -véanse las perforaciones lobulares para colocar pendientes u orejeras-, dicha modificación se llevaba a cabo por la necesidad de sujetarlos. Por lo tanto, ese tipo de transformación no se englobaría dentro de las prácticas tradicionales de embellecimiento corporal por modificación de la fisionomía, como sí lo fueron la decoración dental y la deformación craneana. También es importante tener en cuenta que tanto estas prácticas como la utilización de determinados ornamentos no sólo obedecían a razones estéticas, sino también, y principalmente, a otros motivos, entre ellos la identificación con ciertos grupos sociales y la definición de los roles de género, como más adelante veremos. Por otro lado, la multiplicidad de ornamentos y, a su vez, la abundancia de formas, materiales, técnicas de elaboración y significados de cada uno de ellos, nos lleva necesariamente a acotar el objeto de estudio. Es por ello que en esta ocasión nos adentraremos únicamente en el análisis y estudio de algunas de las joyas más significativas que portaban los miembros de la élite maya y, en concreto, las mujeres.

La selección de estas piezas de joyería ha sido posible tras el análisis preliminar de más de trescientas imáge-

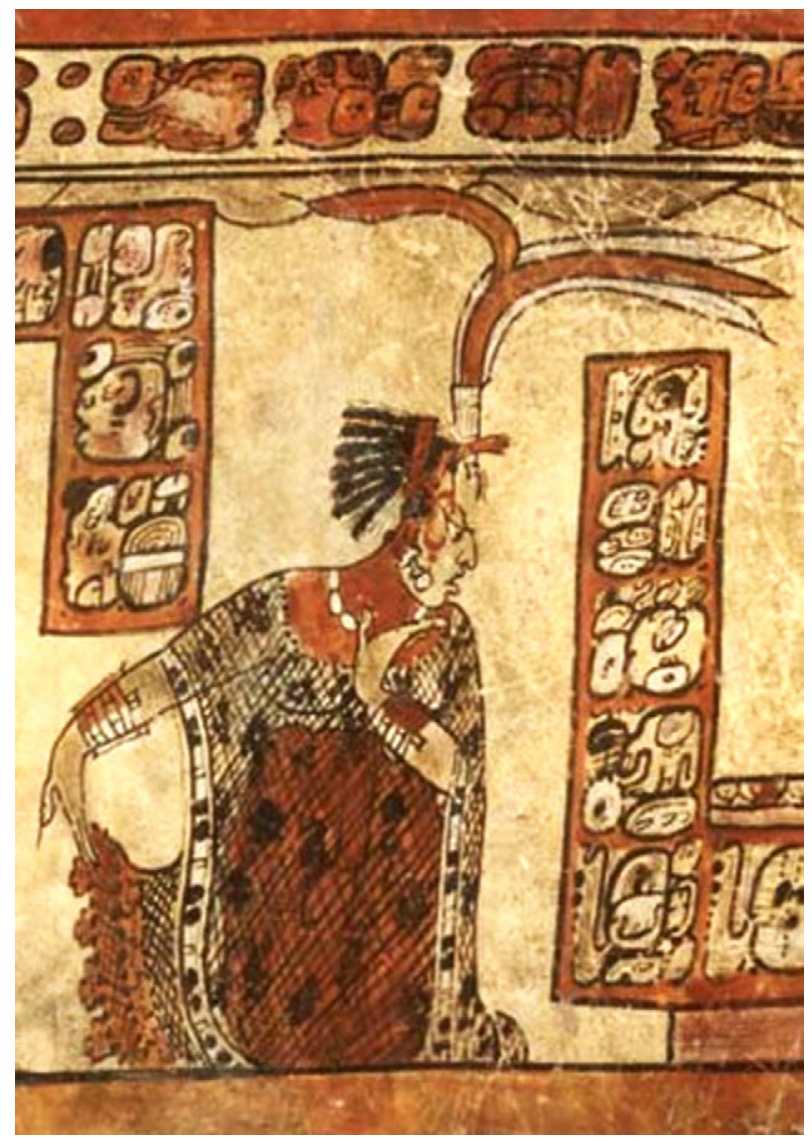

4. Dama de Tikal inclinándose ante un gobernante con la indumentaria propia de las mujeres de la élite, destacando en este caso la transparencia del huipil. Detalle (C) Justin Kerr, K2573, www.mayavase.com)

nes plasmadas en diferentes soportes artísticos, como son las figurillas de cerámica, las vasijas cerámicas polícromas ${ }^{8}$, la pintura mural y los relieves pertenecientes al arte monumental (estelas, dinteles y paneles, sobre todo). En todos ellos aparecen representaciones humanas y, en una importante mayoría, tanto los retratados como las retratadas portan piezas de joyería. Además, los miembros de la élite solían enterrarse ataviados con la rica joyería que utilizaron en vida, de ahí que en ocasiones las mismas joyas que aparecen en las representaciones de estos personajes hayan sido encontradas en las tumbas donde fueron inhumados, pudiéndose así conocer los materiales ${ }^{9}$ y las técnicas con las que fueron confeccionadas.

Una vez realizadas las comparaciones entre las joyas que exhiben los personajes masculinos con las que portan 


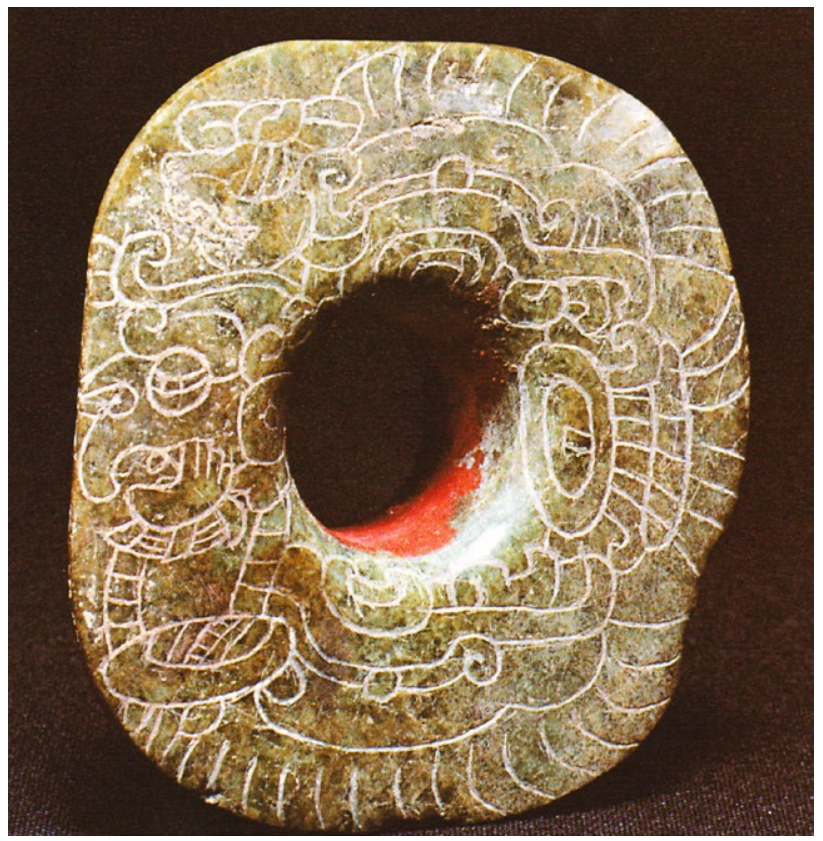

5. Orejera procedente de Río Azul, conservada en el Museo Nacional de Arqueología y Etnología de Guatemala, Inv. n. ${ }^{0} 12.044$ (Vidal ed., 1999: cat.190)

los femeninos se ha podido constatar que hay una mayor variedad de joyas utilizadas sólo por varones y que las empleadas por las mujeres también son utilizadas por ellos. Así, las joyas más significativas en las representaciones de la élite femenina pueden agruparse en las siguientes categorías: orejeras, pulseras, muñequeras, collares, pectorales y otros ornamentos más complejos dispuestos en torno al cuello y sobre el pecho ${ }^{10}$.

Entre las más llamativas, por su tamaño y su ubicación a ambos lados de la cabeza, se encuentran las orejeras, mayoritariamente en forma de discos sujetos a los lóbulos de las orejas por unos tapones o piezas tubulares que los atraviesan. La versión más común remite a la forma del cáliz de una flor y a veces estaban decoradas con tipos iconográficos incisos, alusivos a personajes mitológicos [5]. En otras ocasiones, los miembros de la realeza eran representados con ornamentos auriculares en los que se distingue la cabeza de perfil de una serpiente exhaladora emergiendo del interior de una orejera con forma de flor ${ }^{11}$, como la que porta la protagonista del Dintel 24 de Yaxchilán [1]. Todo ello, sumado a la riqueza de los materiales con que se fabricaban (jade, concha y obsidiana, principalmente), las convirtió en uno de los distintivos con mayor carga simbólica del atuendo.

Las joyas encargadas de engalanar los brazos, como las pulseras y las muñequeras que se aprecian en las representaciones, también solían combinar el empleo de los materiales más preciados por esta civilización, como fueron el jade y las conchas exóticas. Las muñequeras cubrían más de un tercio del antebrazo y se sujetaban anudándolas a éste [2]; su tamaño y diseño permitía el empleo de un mayor número de cuentas que las pulseras, convirtiéndose así en signo de mayor riqueza.

Ahora bien, entre las joyas más destacadas en la indumentaria de las antiguas mujeres mayas de la élite sobresalen las que se colocaban en torno al cuello y sobre el pecho (collares, pectorales y otros ornamentos más complejos). Desde el momento en que el cuerpo es el vehículo de expresión que los seres humanos poseen para mostrarse, tanto el tamaño como el espacio preferente que estas piezas de joyería ocupan en las representaciones artísticas no dejan lugar a dudas de la información sustancial que un minucioso análisis de las mismas puede transmitirnos acerca de sus portadoras.

\section{Collares y pectorales}

Ante todo, es preciso definir los términos collar y pectoral, para poder establecer las diferencias que existen entre ambos. Según el Diccionario de la R.A.E. se entiende por collar el «adorno que ciñe o rodea el cuello», mientras que por pectoral, en la quinta acepción, se indica lo siguiente: «En las antiguas culturas, sobre todo de Egipto y de la América precolombina, adorno que algunos jerarcas llevaban colgado del cuello y que les cubría el pecho o parte de él».

Como decíamos, la mayor parte de los ejemplos analizados proceden de las representaciones de estas piezas en los distintos soportes artísticos, entre ellos las figurillas cerámicas, las vasijas de cerámica policromada ${ }^{12}$, la pintura mural y los relieves escultóricos. En las escenas plasmadas en dichas obras se observan diversos modelos en función de su forma, diseño y complejidad. Así, entre los modelos más sencillos destaca el collar de cuentas que rodea el cuello, sin estar excesivamente ajustado, y que tiene un apéndice que cae por la espalda, concluyendo en un remate tipo borla 
que ejerce como contrapeso [6a]. También existen variantes sin contrapeso o que, siguiendo el mismo patrón, poseen una mayor longitud, a los que habría que añadir los que se anudan y caen por delante.

Este mismo modelo de collar puede tener, además, un colgante de forma generalmente ovalada, predominando entre éstos los colgantes lisos y los que tienen la representación de una efigie [6b].

En el caso de los varones es habitual que en vez de un colgante exhiban pectorales, algunos de ellos de gran tamaño, sin embargo esto rara vez ocurre en las representaciones de mujeres. Ejemplo de pectoral portado por un personaje femenino es el que luce la reina de Tikal en la ya citada vasija K2695 [3, 6c], si bien en este caso el pectoral parece colgar de una gargantilla integrada por cuentas rectangulares, dispuestas de manera que le otorgan a la pieza una apariencia rígida.

Totalmente diferentes son los collares hechos solamente con cordones y que se ajustan al cuello, o los que consisten en un cordón o cinta fina que rodea el cuello de la retratada y exhiben en el centro dos piezas esféricas colocadas una al costado de la otra como únicos motivos decorativos [6d].

\section{Otros ornamentos más complejos dispuestos en torno al cuello y sobre los hombros}

Incluimos en esta categoría aquellos ornamentos dispuestos en torno al cuello que destacan tanto por su riqueza decorativa como por su anchura, puesto que cubren el pecho y parte de los hombros. Debido a ello es difícil determinar si las piezas que formaban parte de estos modelos más complejos se adherían a una base textil, de piel u otro tipo de fibra, o bien si únicamente se ensartaban en varias hileras de hilos o cuerdas finas que se anudaban por los extremos, tal y como hemos observado en el ejemplo de la muñequera [2]. Dado que en los ámbitos más íntimos que aparecen en las escenas pintadas en las vasijas o en la pintura mural no suelen hallarse representaciones de estos tipos de ornamento, debemos recurrir en esta ocasión al arte sobre piedra.

Entre estos se distinguen los que están formados por varias hileras de cuentas dispuestas en torno al cuello de la retratada, abarcando parte de los hombros. Algunos llegan a tener hasta seis hileras, combinando generalmente cuentas

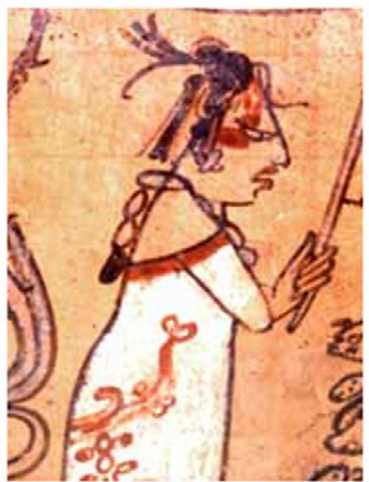

a.

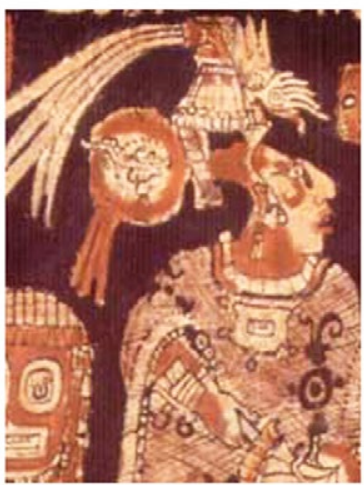

C.

6. Detalle de personajes femeninos luciendo collares y pectorales representados en vasijas cerámicas. a. K5456; b. K6316; c. K2695 d. K8685 (@ Justin Kerr, www.mayavase.com)

de distintos tamaños y formas: esféricas, tubulares y rectangulares [7a].

En otras ocasiones, en la parte frontal de la pieza portan uno o tres medallones. Estos medallones tienen la apariencia de pequeñas máscaras o efigies, suelen estar rodeados de cuentas esféricas y de ellos penden delgadas placas, aparentemente de jade. Los rostros representados en esos medallones parecen corresponder a divinidades o a ancestros divinizados, y su uso debió de estar estrechamente relacionado con el tipo de ceremonia o ritual llevado a cabo por su portadora. Estas preciadas joyas se transmitían por herencia y es habitual encontrarlas en escenas de derramamiento de sangre en las que se invocaba a los ancestros y en las cuales las mujeres de la élite participaban activamente, siendo muy habituales en los monumentos de la región del Usumacinta. También las lucían las muje- 


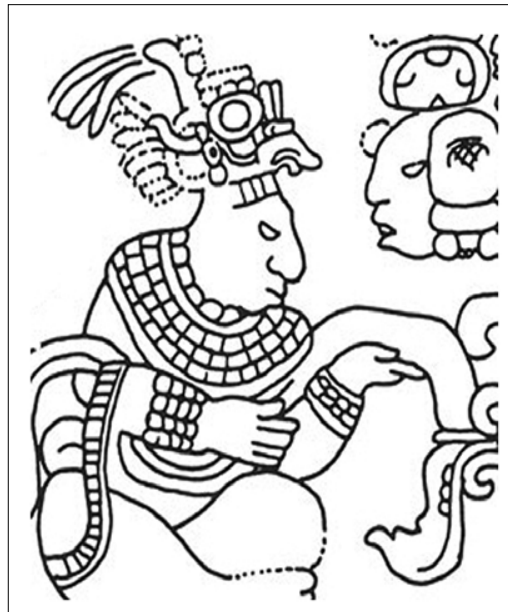

a.
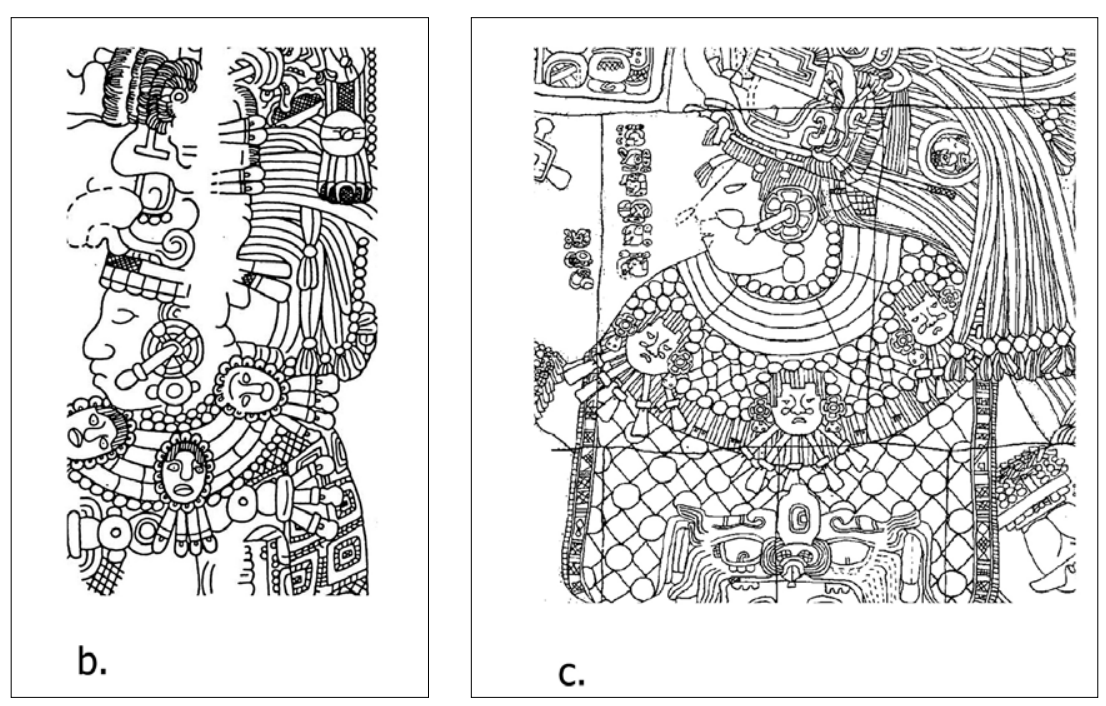

7. Detalle de personajes femeninos con lujosos ornamentos, representados en el arte monumental. a. Escalón 2 de la Escalera Jeroglífica de Yaxchilán; b. Dintel 2 del Templo II de Tikal; c. Estela 34 de El Perú Waka' (a. The Linda Schele Drawings Collection (C) 2000 David Schele 6226; b-c (c) 2000 John Montgomery JM00729; JM00651, www.famsi.org)

res en su rol de esposas o madres de dignatarios durante las ceremonias de transmisión del poder, destacando así su importante papel en las relaciones dinásticas. Un ejemplo paradigmático perteneciente a esta categoría lo constituye el que porta el personaje femenino del Dintel 2 del Templo II de Tikal, conocida como Señora Doce Colas de Guacamaya, y que posee tres máscaras o efigies [7b], o el de una sola efigie que ostenta la Señora Xoc en el ya citado Dintel 24 de Yaxchilán [2].

Las piezas más elaboradas de este tipo de ornamento son las que incorporan los elementos del modelo anterior pero a las que, además, se añade un diseño de red sobre el que se colocaban las mascaritas o efigies ${ }^{13}$. En ocasiones, la minuciosidad era tal que, por ejemplo, podemos apreciar la decoración con flores de cuatro pétalos en las orejeras que portan dichas efigies, como el que luce la reina K'abel, retratada en la Estela 34 de El Perú Waka'14 [7c]. Este tipo de prenda formaba parte del llamado vestido o huipil de red, utilizado en ceremonias que muy posiblemente reproducían episodios del mito del dios del Maíz, protagonizadas en estos casos por mujeres de alto rango como representación de la tierra fértil que produce el maíz ${ }^{15}$. A este respecto, es interesante destacar el hecho de que también hay varones que se hicieron representar portando ese traje típicamente femenino, como el rey Waxaklajun Ub'ah K'awil en la Estela $\mathrm{H}$ de Copán, lo que ha llevado a algunos autores a sugerir que estos trajes estaban asociados con la transmisión de una identidad de género mixta (Joyce, 1996: 182), o lo que es lo mismo, de un tercer género que reunía las identidades del dios del Maíz y de la diosa Luna, ambos portadores del traje de red (Looper, 2002: 174).

Finalmente, hemos de señalar que en ocasiones se combinaba el uso de distintas piezas de joyería a la vez, incrementando así la riqueza ornamental de sus portadoras, como es el caso del personaje femenino esculpido en el Panel del Museo de Arte de Cleveland [8a] o de los representados en la Estela 2 de Bonampak [8b].

\section{Epílogo}

El análisis de los ornamentos dispuestos en torno al cuello y sobre el pecho que lucen los personajes femeninos representados en el arte maya nos ha permitido distinguir diferentes categorías tipológicas a las cuales adscribirlos, con el fin de facilitar su clasificación. Ello nos ha permitido también 
8. a. Protagonista femenina del Panel del Museo de Arte de Cleveland (C 2000 John Montgomery JM00903, www.famsi.org). b. Gobernante Chan Muan (figura central) entre su mujer y su madre (figuras izquierda

y derecha, respectivamente). Estela 2 de Bonampak (Mathews, 1980: 62, fig. 2)

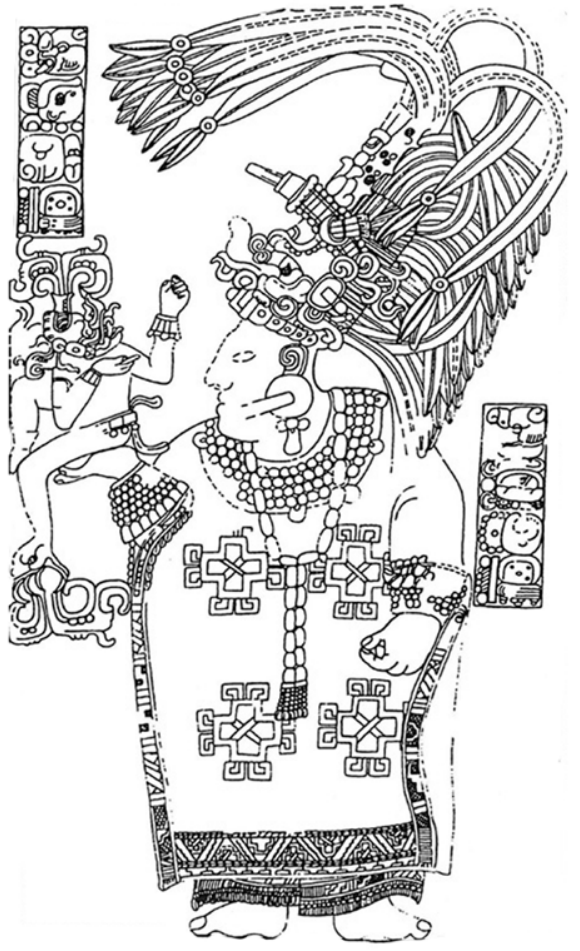

a.

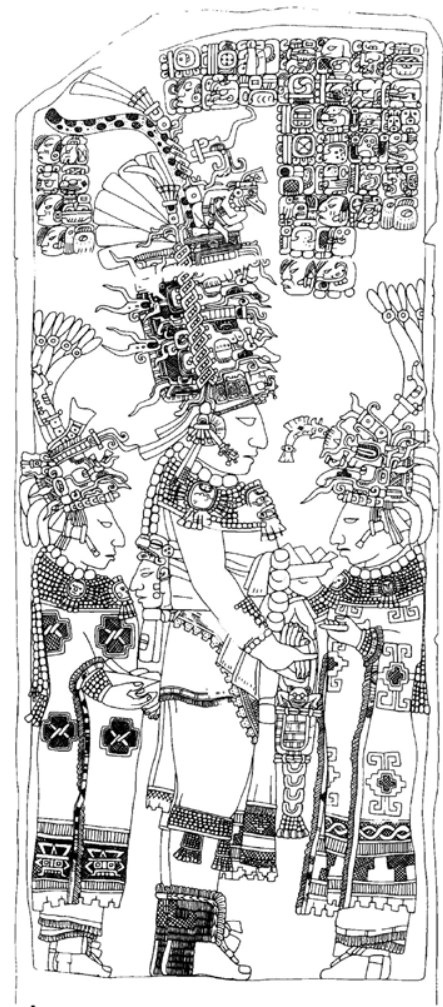

b. constatar la inexistencia de un consenso entre los investigadores a la hora de denominar estas piezas, de ahí que en la literatura exista cierta confusión a la hora de diferenciar entre collar y pectoral y, sobre todo, en la terminología relativa a los ornamentos más complejos, considerados por algunos como prendas de vestir y, por otros, como joyas ${ }^{16}$.

No obstante, el objetivo de este trabajo pretendía ir más allá y obtener, a través de estas piezas, información sobre quiénes las portan con el fin de abordar la cuestión de los roles y las relaciones de género entre los miembros de la élite maya del período clásico.

En este sentido, hemos comparado de forma minuciosa estos tipos de ornamentos empleados por mujeres con los que lucen sus compañeros varones, especialmente cuando ocupan una misma representación. Por otro lado, hemos tenido en cuenta el tipo de soporte en que fueron plasmadas estas imágenes ya que los mensajes que pretendían transmitir varían notablemente en función de si se trata de una figurilla cerámica, una escena pintada en una vasija o una pintura mural, en contraste con las talladas en estelas, dinteles o paneles, las cuales transmiten mensajes aún más conceptuales, condensando de este modo un mayor número de significados políticos y religiosos.

Tal como ya habíamos comprobado en anteriores trabajos (Vázquez de Ágredos, Vidal y Horcajada, en prensa), el

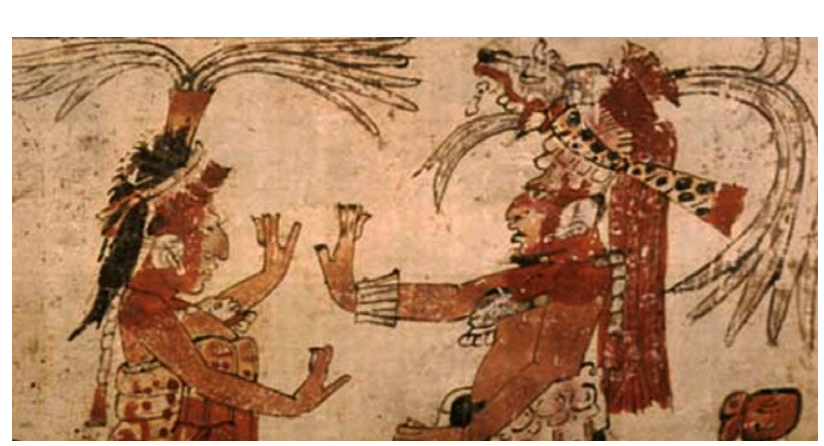

9. Pareja de mujer y hombre realizando una danza ritual. Ambos lucen collares con colgante tipo efigie. Detalle (C) Justin Kerr 0554, www.mayavase.com) 


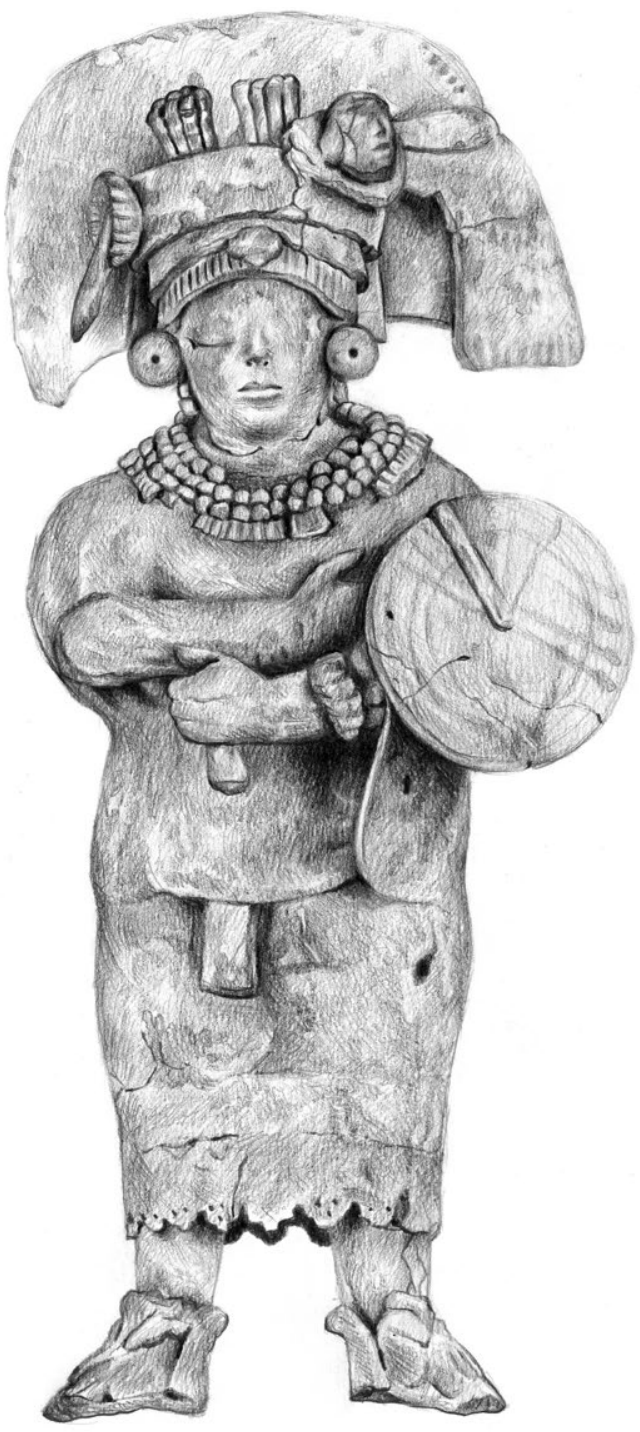

10. Figurilla con representación de Kalo'mte' K'abel de El Perú Waka', ataviada como guerrera, conservada en el Museo Nacional de Arqueología y Etnología de Guatemala (dibujo de Gaspar Satorres Gil)

número de representaciones femeninas en dichos soportes artísticos es muy inferior al de las masculinas, lo que obviamente responde a un mayor protagonismo de los varones en los acontecimientos más representativos de la sociedad maya, pero sin que ello suponga el que las mujeres tuvieran vedado su acceso a los mismos, de ahí la necesidad de sacar a relucir las historias de todas esas mujeres, cuya importancia ha quedado ensombrecida en la historiografía hasta época reciente.

De acuerdo con ello, hemos podido constatar que los adornos femeninos para el cuello son semejantes a los de los hombres, al menos en la mayoría de los casos estudiados. Los collares de cuentas son los modelos más utilizados por ambos sexos, siendo el más común aquel del que pende un colgante ovalado o una efigie [9]. Por su parte, los ornamentos más complejos también responden a patrones similares, e incluso idénticos, tanto en los retratos femeninos como en los masculinos [8b]. No obstante, mientras que la mayoría de diseños de estos ornamentos femeninos se repiten, aunque con ligeras diferencias, en retratos de hombres, existe otro amplio abanico de joyas de las que no encontramos equivalentes femeninos, lo cual es debido en parte a la mayor abundancia de representaciones del sexo opuesto.

En lo que respecta al tipo de soporte al que pertenecen las imágenes, la presencia de collares y pectorales femeninos es más frecuente en las figurillas y en las escenas de carácter íntimo que predominan en las vasijas de cerámica polícromas. En estos casos es interesante destacar que la representación de dos mujeres en una misma escena con tipos de collares diferentes puede ser indicativo de la diferenciación social entre ambas o incluso revelar sus oficios, como ocurre con el mencionado «Vaso Salomé» (K2695) [3], en el que el atuendo y los ornamentos de la reina, especialmente el pectoral, la distinguen claramente de la cortesana representada a su derecha.

Los compuestos por varias hileras de cuentas es posible encontrarlos tanto en representaciones pertenecientes al arte privado (figurillas) -siendo éste el caso del que porta Kalo'mte' K'abel de Perú Waka', ataviada como guerrera [10]-, como en los monumentos pétreos. Por el contrario, la representación de mujeres con piezas de este tipo pero con mascaritas o efigies adheridas está exclusivamente reservada al arte monumental. Este hecho nos permite llegar a la conclusión de que el uso de estos complejos ornamentos está íntimamente ligado a la participación de sus portadores en los acontecimientos políticos y religiosos más significativos de esta cultura (rituales de derramamiento de sangre $u$ otras sustancias, ceremonias de transmisión del poder real y de reconocimiento del heredero, conmemoraciones calendáricas y astronómicas, etc.), representados ex profeso en 
el arte oficial sobre piedra, en los cuales sí hubo mujeres que alcanzaron un alto nivel de protagonismo. Comprobamos también cómo cada uno de estos acontecimientos exigía un atuendo y ornamentos determinados y cómo éstos eran transmitidos de una generación a otra.

Por consiguiente, el minucioso análisis de estas joyas contribuye a reforzar la hipótesis defendida por otros autores de la existencia de un nivel de igualdad entre hombres y mujeres en determinados ámbitos de la sociedad maya algo mayor del que los estudios del pasado defendían, puesto que las figuras femeninas no sólo contaron con un canon de representación propio, sino que además fueron varias las que tuvieron el privilegio de utilizar piezas de joyería transmisoras de una elevada carga simbólica y del estatus de sus portadoras, llegando incluso a personificar a deidades tan importantes como el dios del Maíz. Es en estos casos cuando las representaciones de mujeres pueden confundirse con las de los varones y viceversa, de ahí la dificultad que tuvieron los exploradores decimonónicos a la hora de realizar las primeras descripciones de los monumentos que hallaron en las ciudades mayas recién descubiertas, tal como mencionábamos al inicio de este trabajo.

En suma, dichos resultados se conforman únicamente como el primer paso a dar en vistas a una futura investigación de mayor envergadura que permita, desde una perspectiva de género, poner en valor la verdadera historia de las antiguas mujeres mayas de alto rango y la función que desempeñó el arte en la construcción de su imagen de poder.

\section{Agradecimientos}

Las autoras agradecen expresamente el apoyo del Ministerio de Economía y Competitividad, a través de la financiación del proyecto de investigación con número de referencia BIA2014-53887-C2-2, que ha contribuido de forma determinante a hacer posible la presente investigación, así como a Gaspar Muñoz Cosme y a Patricia Horcajada Campos por sus acertados comentarios y sugerencias durante la realización de este trabajo.

\section{Notas}

1 De hecho, en la descripción que realiza este autor del Dintel 24 de Yaxchilán, considera que el personaje que hoy conocemos como la Señora Xoc es un varón y no una mujer: «L'un des personnages, l'homme agenouillé, un prêtre sans doute, s'est passé une corde au travers de la langue et il l'a garnie d'épines...» (Charnay, 1885: 392).

2 Bruhns y Stothert, 1988: 18; Klein, 2001: 3; y Ardren, 2002: 6.

3 Teoría compartida por el arqueólogo Asier Rodríguez, quien se pregunta si estas esposas reales, originarias de lugares que en épocas anteriores habían sido considerados enemigos de su nuevo lugar de destino, no eran acaso parte de un botín de guerra (Rodríguez-Shadow y López, 2011: 215).

4 Las ideas centrales de este capítulo ya habían sido expuestas por la autora en varias reuniones científicas desde el año 1992.

5 Para un completo estado de la cuestión sobre la figura femenina y el género en el área maya, véase la Tesis de Maestría de Pía Moya (2006).

6 Según Taylor (1983: 72-73), esta prenda textil de tradición teotihuacana y nombre náhuatl fue importada del Centro de México por los mayas en el Clásico Temprano.

7 Para un estudio más detallado acerca del simbolismo de la indumentaria femenina, véase Joyce (1992).

8 La base de datos elaborada por Justin Kerr (www.mayavase.com) permite visualizar una enorme cantidad de representaciones mayas que fueron plasmadas sobre vasijas cerámicas, muchas de las cuales no serían accesibles de otro modo, ya que pertenecen a coleccionistas privados. Además, gracias a la técnica del roll out empleada por dicho fotógrafo, estas representaciones se pueden observar completas en un solo plano.

9 Los materiales más habituales empleados en la manufactura de los ornamentos de la élite fueron el jade y la concha Spondylus. El jade es el término genérico empleado para designar dos rocas metamórficas distintas: la nefrita y la jadeíta. La empleada en el área maya es la jadeíta, siendo el Valle del Motagua en Guatemala la fuente principal, y seguramente única, de donde se extraía este mineral. Por su parte, la concha Spondylus es un bivalvo que abunda tanto en las aguas tropicales de la región malacológica Panámica-Pacífica como en la región Caribe. Se caracteriza por su hermosa coloración rosácea y por la presencia de espinas en su parte externa.

10 No hemos incluido en esta categoría los cinturones, si bien en algunas ocasiones los elaborados con materiales preciosos podrían ser considerados como joyas.

11 Sobre el simbolismo de la orejera como conducto de donde brota el aliento sagrado, véase Taube (2005: 32-43).

12 De las más de 300 imágenes analizadas para este estudio, 262 proceden de vasijas cerámicas, de las cuales 172 cuentan con representaciones antropomorfas, aunque no siempre en contextos terrenales. De éstas, 157 son imágenes con representaciones de individuos que portan ornamentos en torno al cuello, siendo de destacar la preponderancia de personajes masculinos con respecto a los femeninos. Así, 99 imágenes están ocupadas por varones, 52 por individuos de ambos sexos y sólo 6 de ellas otorgan protagonismo exclusivamente al género femenino. Asimismo, en las imágenes en las que hombres 
y mujeres aparecen por igual, únicamente en 15 lo hacen de manera equitativa, pues en 29 son mayoría las figuras masculinas, y sólo en 8 las mujeres están más representadas.

13 Algunos autores se refieren a este tipo de atavío como capa, quechquémitl (véase nota 6) o suyem (nombre con el que se designa a la capa en maya yucateco), sin embargo no se trata de prendas textiles sino de piezas de joyería que, además, no están abiertas por delante, de ahí que dichos términos no nos parezcan del todo adecuados. El hallazgo en la Tumba 1 de la Estructura XV de Calakmul de un entramado de cuentas de concha Spondylus podría ser indicador de que éste era el material empleado para la confección de los diseños de red (García y Vázquez, 2012: fig. 9d).

14 En esta estela el nombre de la reina aparece acompañado del título Kalo'mte', el cual estaba generalmente reservado a reyes poderosos, pudiendo traducirse como "guerrero supremo».

15 Sobre el simbolismo del traje de red o enrejado, véase Joyce, 1992, 1996; Le Fort, 2002: 33-35; García y Vázquez, 2012 : 65 y ss.

16 Véase nota 13.

\section{Bibliografía}

ARDREN, Traci (2002), «Women and Gender in the Ancient Maya World», en ARDREN, Traci (ed.), Ancient Maya women, Altamira Press, Walnut Creek, pp. 1-11.

BARBA AHUATZIN, Beatriz (2011), «Edad y género en el Popol Vuh», en RODRíGUEZ-SHADOW, María J. y LÓPEZ HERNÁNDEZ, Miriam (eds.), Las mujeres mayas en la Antigüedad, Centro de Estudios de Antropología de la Mujer, México, pp. 158-208.

BRUHNS, Karen O. y STOTHERT, Karen E. (1988), Women in Ancient America, University of Oklahoma Press, Norman.

CHARNAY, Désiré (1885), Les anciennes villes du Nouveau Monde, Hachette, París.

GARCÍA BARRIOS, Ana y VÁZQUEZ LÓPEZ, Verónica (2012), «The Weaving of Power: Women's Clothing and Protocol in the Seventh-Century Kingdom of Kaanu'l», Latin America Indian Literatures Journal, vol. 27, n. ${ }^{\circ}$ 1: pp. 50-95.

GARCÍA VALGAÑÓN, Rocío (2015), El papel de las ancianas mayas prehispánicas a través de la lconografía. Tesis doctoral inédita, Universidad Complutense de Madrid, Madrid.

GUENTER, Stanley y FREIDEL, David (2005), «Warriors and Rulers: Royal Women of the Classic Maya», en BRETELL, Carolyn y SARGENT, Carolyn (eds.), Gender in Crosscultural Perspectives, Prentice Hall, Nueva Jersey, pp. 74-80.

HENDON, Julia, (1997), "Women's Work, Women's Space, and Women's Status among the Classic-Period Maya Elite of the Copan Valley», en CLASSEN, Cheryl y JOYCE, Rosemary A. (eds.), Women in Prehistory: North America and Mesoamerica, University of Pennsylvania Press, Filadelfia, pp. 33-46.

JOSSERAND, Kathryn (2011), «Las mujeres en los textos del maya Clásico», en RODRÍGUEZ-SHADOW, María J. y LÓPEZ HERNÁNDEZ, Miriam (eds.), Las mujeres mayas en la Antigüedad, Centro de Estudios de Antropología de la Mujer, México, pp. 107-137.

JOYCE, Rosemary A. (1992), «Dimensiones simbólicas del traje en monumentos clásicos mayas: la construcción del género a través del vestido», en ASTURIAS DE BARRIOS, Linda y FERNÁNDEZ GARCÍA, Dina (eds.), La indumentaria y el tejido mayas a través del tiempo, Ediciones del Museo Ixchel, Guatemala, pp. 29-38.

- (1996), «The Construction of Gender in Classic Maya Monuments», en WRIGHT, Rita (ed.), Gender and Archaeology: Essays in Research and Practice, University of Pennsylvania Press, Filadelfia, pp. 167-195.

- (2001), Gender and Power in Prehispanic Mesoamerica, University of Texas Press, Austin.

KLEIN, Cecelia F. (2001), «Introduction», Gender in Prehispanic America, Dumbarton Oaks, Washington, pp. 1-14.

LE FORT, Geneviève (2002), «El traje real entre los mayas de la época Clásica (250-900 d. C.)», en SOLANILLA DEMESTRE, Victòria (ed.), Actas de las II Jornadas internacionales sobre textiles precolombinos, Universitat Autònoma de Barcelona e Institut Català de Cooperació Iberoamericana, Barcelona, pp. 27-41.

LOOPER, Matthew G. (2002), «Women-Men (and Men-Women): Classic Maya Rulers and the Third Gender», en ARDREN, Traci (ed.), Ancient Maya women, Altamira Press, Walnut Creek, pp. 171-202.

LÓPEZ HERNÁNDEZ, Miriam (2011), «Representaciones de vida y muerte en torno a la menstruación entre los mayas y otros grupos mesoamericanos", en RODRÍGUEZ-SHADOW, María J. y LÓPEZ HERNÁNDEZ, Miriam (eds.), Las mujeres mayas en la Antigüedad, Centro de Estudios de Antropología de la Mujer, México, pp. 231-250. 
MARCUS, Joyce (1976), Emblem and State in the Classic Maya Lowlands, Dumbarton Oaks, Washington.

MARTIN, Simon y GRUBE, Nikolai (2000), Chronicle of the Maya Kings and Queens. Deciphering the Dynasties of the Ancient Maya, Thames and Hudson, Londres.

MATHEWS, Peter (1980), «Notes on the dynastic sequence of Bonampak, Part 1», en ROBERTSON, Merle G. (ed.), Third Palenque Round Table, 1978, Part 2, University of Texas Press, Austin, pp. 60-74.

MAUDSLAY, Alfred P. (1974/1889-1902), Biologia Centrali-Americana, Vols. I-VI, Milpatron Publishing Corp., Nueva York.

MILLER, Virginia (ed.) (1988), The Role of Gender in Precolumbian Art and Architecture, University Press of America, Lanham.

MOLLOY, John P. y RATHJE, William J. (1974), «Sexploitation among the Late Classic Maya», en HAMMOND, Norman (ed.), Mesoamerican Archaeology; New Approaches, Duckworth, Londres, pp. 431-444.

MOYA HONORES, Pía (2006), La representación material de los roles femeninos y las relaciones de género en las figurillas de la isla de Jaina, Tesis de Maestría, UNAM, México.

NASH, June (2002), «Preface», en ARDREN, Traci (ed.), Ancient Maya women, Altamira Press, Walnut Creek, pp. ix-xiv.

PROSKOURIAKOFF, Tatiana (1961), «Protraits of Women in Maya Art», en LOTHROP, Samuel K. et al (ed.), Essays in Pre-Columbian Art and Architecture, Harvard University Press, Cambridge, pp. 81-99.

RODRíGUEZ-SHADOW, María J. (2011), «Las mujeres en la antigua cultura maya», en RODRíGUEZ-SHADOW, María J. y LÓPEZ HERNÁNDEZ, Miriam (eds.), Las mujeres mayas en la Antigüedad, Centro de Estudios de Antropología de la Mujer, México, pp. 209-229.

RODRÍGUEZ-SHADOW, María J. y KELLOG, Susan (2013), «Los aportes de Rosemary A. Joyce a la Arqueología de Género en Mesoamérica”, en RODRÍGUEZ-SHADOW, María J. y LÓPEZ HERNÁNDEZ, Miriam (eds.), Género y Arqueología en Mesoamérica. Homenaje a Rosemary A. Joyce, Centro de Estudios de Antropología de Género, México, pp. 19-20.

- (eds.) (2013), Género y Arqueología en Mesoamérica. Homenaje a Rosemary A. Joyce, Centro de Estudios de Antropología de Género, México.

SCHELE, Linda y MILLER, Mary E. (1988/1986), The Blood of Kings: Dynasty and Ritual in Maya Art, Thames and Hudson, Londres y Nueva York.

SHARER, Robert J. y TRAXLER, Loa P. (2006), The Ancient Maya, Standford University Press, Stanford.

TAUBE, Karl (2005), «The Symbolism of Jade in Classic Maya Religion», Ancient Mesoamerica, n. ${ }^{\circ}$ 16, pp. 23-50.

TAYLOR, Dicey (1983), Classic Maya Costume: Regional Types of Dress, Tesis doctoral inédita, Yale University, Yale.

VÁZQUEZ DE ÁGREDOS PASCUAL, M. ${ }^{a}$ Luisa, VIDAL LORENZO, Cristina y HORCAJADA CAMPOS, Patricia (en prensa), «Face painting among the Classic Maya Elites. An iconographic study", en TIESLER, Vera y LOZADA, M. Cecilia, Social Skins of the Head: Body Beliefs and Ritual in Ancient Mesoamerica and the Andes, University of New Mexico Press, Albuquerque.

VIDAL LORENZO, Cristina (2005), «La mujer maya y su papel político y religioso», en ALFARO, Carmen y TÉBAR, Estíbaliz (eds.), Protai Gynaikes: mujeres próximas al poder en la Antigüedad, SEMA V-VI, Universidad de Valencia, Valencia, pp. 173-185.

- (ed.) (1999), Los Mayas. Ciudades milenarias de Guatemala, Catálogo de la exposición. Ministerio de Educación y Cultura, Generalitat Valenciana y Ayuntamiento de Zaragoza, Zaragoza. 
